\title{
DISTRIBUCIÓN DE LA RENTA EN ESPAÑA: 2004-2013
}

\author{
Recibido: 22 de abril de 2016 • Aprobado: 15 de diciembre de 2016 \\ DOI: $10.22395 /$ seec.v20n42a2
}

\section{Francisco J. Goerlich ${ }^{* *}$}

\section{RESUMEN}

Este documento presenta una revisión sobre la evolución de la distribución de la renta en España en el período 2004-2013. El objetivo es examinar el papel que ha jugado el mercado de trabajo en el incremento de las desigualdades, así como el efecto que han tenido las diversas actuaciones públicas a través de transferencias monetarias, impuestos directos y el suministro de servicios públicos en especie. En la metodología se usan índices clásicos de desigualdad aplicados a la Encuesta de Condiciones de Vida. Se concluye que durante este período el incremento en las desigualdades puede atribuirse con nitidez al deterioro del mercado de trabajo tras la crisis de 2007.

\section{PALABRAS CLAVE}

Distribución de la renta; mercado laboral; políticas públicas; impuestos; transferencia; España.

\section{CLASIFICACIÓN JEL}

E24, E64, H24, H40, J08

\section{CONTENIDO}

Introducción; 1. Aspectos conceptuales y metodológicos; 2. Renta de mercado; 3. El papel redistributivo de prestaciones sociales e impuestos directos; 4. Provisión de servicios públicos en especie: Servicios de salud y Educación; 5. Conclusiones; Bibliografía.

\footnotetext{
* Este artículo es producto del proyecto de investigación "Distribución de la Renta. Crisis Económica y Políticas Redistributivas", que hace parte del programa de investigación de la Fundación BBVA-Ivie (Instituto Valenciano de Investigaciones Económicas). La investigación fue realizada entre septiembre de 2015 y febrero de 2016. También se enmarca en el proyecto del Ministerio de Economía y Competitividad de España ECO2015-70632-R.

"* Economista, Universidad de Valencia, Valencia, España. MSc in Economics, London School of Economics, University of London, Londres, Reino Unido. Doctor en Economía por la Universidad de Valencia, Valencia, España. Profesor del Departamento de Análisis Económico, Universidad de Valencia, Valencia, España. Correo electrónico: francisco.j.goerlich@uv.es.
} 


\section{INCOME DISTRIBUTION IN SPAIN: 2004-2013}

\section{ABSTRACT}

This paper analyses the evolution of Spain's income distribution between 2004-2013. The main purpose is to examine the role that the labor market played in the inequality gap increase, as well as the role that several public actions played via monetary transactions, direct taxes, and public services supplied in kind. The methodology uses several classical inequality indicators, which appear on the Standard of Living Survey. The results lead to the conclusion that inequality increases are closely related to the labor market deterioration that arose after the 2007 crisis.

\section{KEY WORDS}

Income distribution; labor market; , public policies; taxes; transfer; Spain.

\section{JEL CLASSIFICATION}

E24, E64, H24, H40, J08

\section{CONTENT}

Introduction; 1. Conceptual and methodological aspects; 2. Market income; 3 . The redistributive role that direct taxes and social benefits have; 4. Public Services supplied in kind; Educational and Health Services; 5. Conclusions; Bibliography.

\section{DISTRIBUIÇÃO DA RENDA NA ESPANHA: 2004-2013}

\section{RESUMO}

Este documento apresenta uma revisão sobre a evolução da distribuição da renda na Espanha no período 2004-2013. O objetivo é examinar o papel que há jogado o mercado de trabalho no incremento das desigualdades, assim como o efeito que há tido as diversas atuações públicas a través de transferências monetárias, impostos diretos e o subministro de serviços públicos em espécie. Na metodologia se usam índices clássicos de desigualdade aplicados à Enquete de Condições de Vida. Se conclui que durante este período o incremento nas desigualdades pode atribuir-se com nitidez à deterioração do mercado de trabalho após a crise de 2007.

\section{PALAVRAS CHAVE}

Distribuição da renda; mercado laboral; políticas públicas; impostos; transferência; Espanha.

\section{CLASSIFICAÇÃO JEL}

E24, E64, H24, H40, J08

\section{CONTEÚDO}

Introdução; 1. Aspectos conceituais e metodológicos; 2. Renda de mercado; 3. O papel redistributivo de prestações sociais e impostos diretos; 4. Provisão de serviços públicos em espécie: Serviços de saúde e Educação; 5. Conclusões; Bibliografia. 


\section{INTRODUCCIÓN}

España ha sido uno de los países europeos que ha sufrido la crisis económica de la primera década del siglo XXI con mayor severidad. Así lo afirma la OCDE (2014 y 2015). En la práctica ello se ha traducido en una drástica caída en los niveles medios de renta y una distribución muy asimétrica de la carga de la crisis. El resultado ha sido un crecimiento notable de la desigualdad, que se sitúa, a mediados de la segunda década del siglo XXI, en niveles récord desde que se dispone de encuestas de hogares. Este trabajo examina la evolución reciente en la distribución de la renta, antes y durante la crisis, así como cuál ha sido el papel moderador que ha jugado el sector público en suavizar estas desigualdades a través de diversas políticas.

De acuerdo con la Encuesta de Condiciones de Vida (ECV) la renta disponible de los hogares cayó en promedio un $20 \%$ entre 2007 y 2013. Se interrumpe de esta forma un largo período de crecimiento sostenido de los niveles de vida -entre 2004 y 2007, dichas rentas crecieron algo más del 5 \%-. Sin embargo, esta caída en el nivel vida del hogar medio esconde grandes disparidades individuales. El gráfico 1 muestra dos indicadores habituales en el análisis de la distribución de la renta,

\section{Gráfico 1. Indicadores de desigualdad. Renta disponible equivalente per cápita}

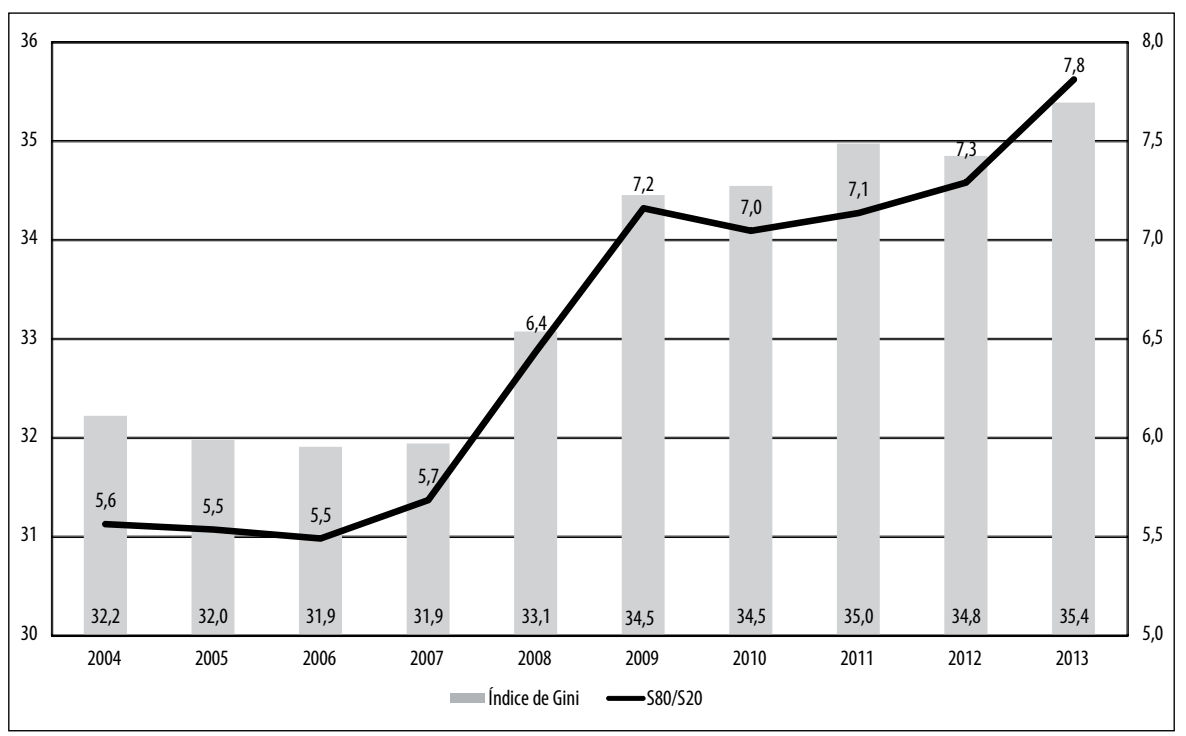

Fuente: elaboración propia a partir de la ECV

1 Para un panorama de largo plazo véanse los excelentes trabajos de Prados de la Escosura (2008) y Ayala (2013, 2014, 2016), y para un análisis reciente mucho más detallado Goerlich (2016).

El papel redistributivo del sector público ha sido también objeto de atención en varios trabajos de países de América Latina, como por ejemplo los de Lusting y Pessino (2014), Higgins y Pereira (2014), Jaramillo (2014) o Bucheli et al. (2014). 
(i) el índice de Gini, y (ii) el cociente entre el porcentaje de renta que disfruta el $20 \%$ más rico de la sociedad frente al $20 \%$ más pobre, lo que se conoce como el índice S80/S20. El mensaje fundamental es claro: con el comienzo de la crisis en 2007, la distribución de la renta disponible empeora notablemente, de forma brusca al principio, y con una ligera tendencia creciente desde entonces.

Como los índices de desigualdad del gráfico 1 son relativos, es decir, todo lo que importa en su evolución son las variaciones relativas de los hogares en relación con la variación del nivel de vida agregado, es posible examinar el origen del crecimiento de las desigualdades a partir de las curvas de incidencia. Dichas curvas nos indican la variación de los niveles de renta por percentiles de la distribución en relación con la variación agregada, y nos permiten examinar qué estratos de la distribución contribuyen al aumento o disminución de la desigualdad.

Gráfico 2. Crecimiento relativo al promedio nacional de la renta disponible equivalente per cápita por percentiles

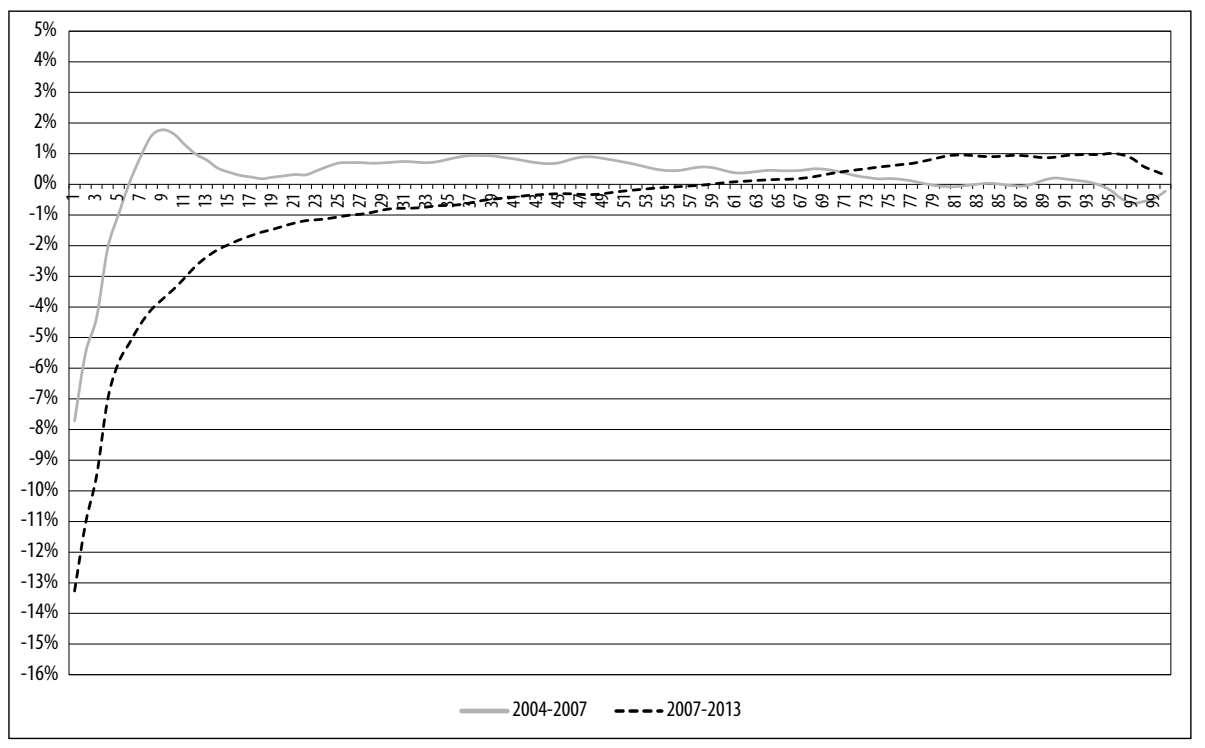

Fuente: elaboración propia a partir de la ECV

La curva de incidencia para el período 2004-2007 muestra que el crecimiento anterior al inicio de la crisis no favoreció a todos los estratos de la sociedad; en concreto, los primeros percentiles perdieron posiciones relativas en un contexto de crecimiento generalizado - gráfico 2-. Sin embargo, a partir del percentil seis se observa un crecimiento por encima del promedio, mientras que el último quintil de la distribución parece neutro. Por el contrario, la curva de incidencia para el período 2007-2013 muestra un comportamiento claramente a favor de la desigualdad, con 
una asimetría muy marcada. La primera mitad de la distribución pierde posiciones en términos relativos, especialmente los estratos más bajos, mientras que a la segunda mitad de la distribución le sucede justo lo contrario. Ello indica que la carga de la crisis ha caído sobre los estratos más bajos de renta.

Para darnos cuenta de hasta qué punto la distribución se ha polarizado en el período de crisis, conviene restaurar el crecimiento a las curvas de incidencia del gráfico 2. Puesto que el crecimiento es positivo en el primer sub-período, 2004-2007, pero negativo en el segundo, 2007-2013, ambas curvas se distancian -gráfico 3-. En los años anteriores a la crisis casi todos los estratos mejoraban en términos de crecimiento de sus rentas, aunque los primeros percentiles no lograban mejorar su situación relativa a pesar del crecimiento general. En el período 2007-2013 todos los estratos empeoran su situación, ya que muestran caídas de renta en el conjunto del período, pero los estratos inferiores muestran un descenso de su nivel de vida considerable.

\section{Gráfico 3. Crecimiento de la renta disponible equivalente per cápita por percentiles}

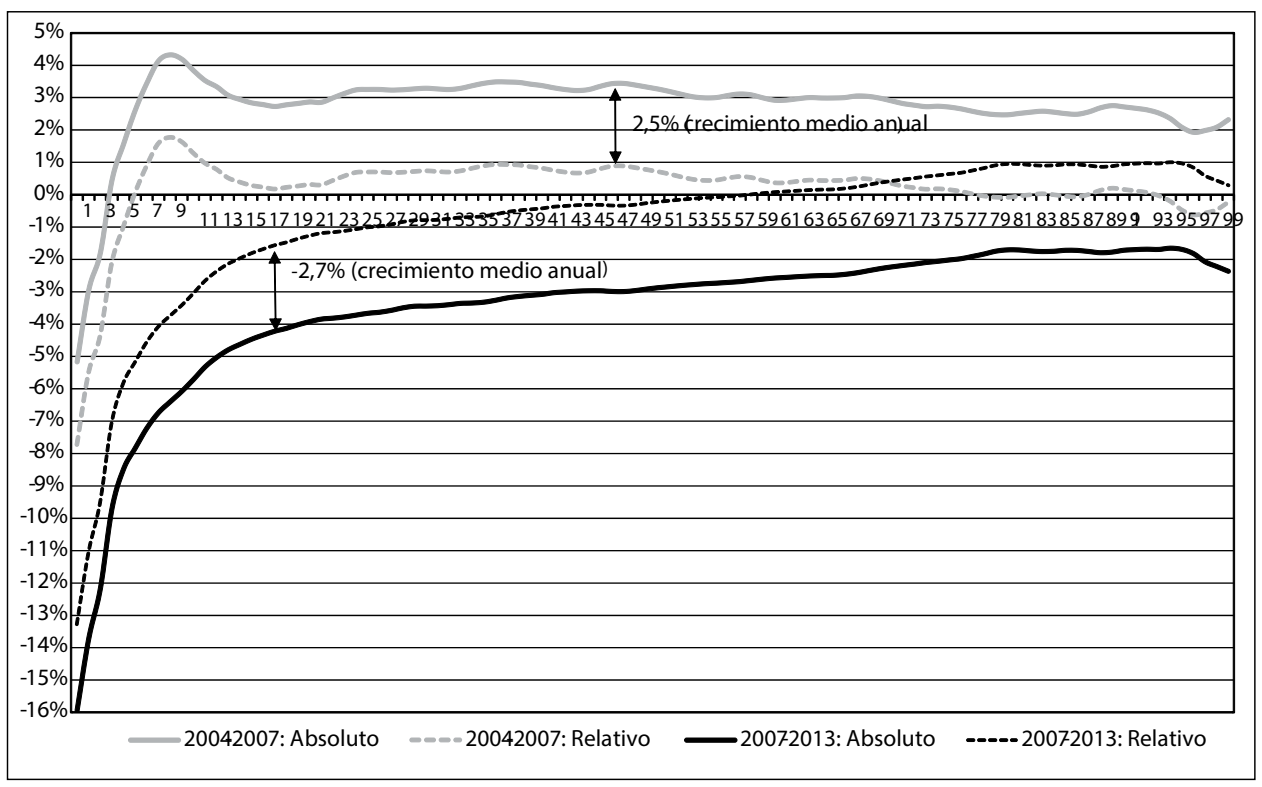

Fuente: elaboración propia a partir de la ECV

Este pequeño resumen sobre la evolución de la distribución de la renta en la crisis toma como punto de partida la renta disponible, que es la definición habitual en este contexto. Es la renta disponible sobre la que los hogares tienen capacidad de actuación para sus decisiones de consumo y ahorro; sin embargo, el proceso de 
generación de rentas tiene lugar mucho antes, cuando los individuos acuden a los mercados para obtener rentas, que luego son agregadas en hogares, que reciben transferencias, privadas y/o públicas y, además, pagan impuestos. Como resultado de todo este proceso, la distribución inicial de la renta generada en el mercado se ve profundamente alterada por las intervención del sector público vía impuestos y transferencias monetarias, así como por la propia demografía de los hogares. Estas actuaciones, sin embargo, no agotan los efectos que el sector público tiene sobre los niveles de vida de los ciudadanos, y la distribución de los mismos.

En las economías desarrolladas el sector público proporciona una parte importante de servicios públicos que no son pagados directamente por sus usuarios, sino financiados mediante impuestos, básicamente, educación y servicios de salud, pero también otros servicios sociales, muchos de ellos suministrados por las entidades locales. Estas transferencias en especie no son consideradas normalmente en los análisis distributivos, porque su incorporación a la renta del hogar es difícil y requiere supuestos en muchos casos discutibles o de difícil justificación. Sin embargo, tal y como han señalado Stiglitz, Sen y Fitoussi (2009) y otros autores, es esta noción de renta disponible extendida o ajustada la que debería ser objeto de atención por parte de los análisis sobre el nivel de vida y su distribución.

El objeto de este documento es analizar la distribución de la renta desde esta perspectiva, es decir, partir de las rentas primarias generadas en el mercado y ver cómo las sucesivas actuaciones del sector público van modificado el nivel y la distribución de los niveles de vida a partir de la información suministrada por la ECV, para el período 2004-2013, y las estadísticas sobre el gasto público en servicios de salud y educación. Utilizaremos para ello índices habituales en la literatura sobre desigualdad, fundamentalmente el índice de Gini. Ello permite resaltar el papel fundamental del mercado de trabajo en la determinación de la distribución de la renta de los hogares, así como el papel de las políticas públicas en mejorar la distribución de la renta generada por el mercado.

La estructura del trabajo es la siguiente. A continuación se concreta el marco conceptual de análisis y se indican las opciones metodológicas. El apartado 3 analiza la renta de mercado, y el 4, cómo la actuación del sector público, vía impuestos y transferencias, modifica esta renta inicial determinada en el mercado. El apartado 5 explora, tentativamente, cómo el hecho de imputar rentas en servicios de salud y educativas a los hogares modifica nuestra visión de la evolución de dichas rentas, tanto en niveles como en dispersión. En el apartado final se presentan las conclusiones del trabajo. 


\section{ASPECTOS CONCEPTUALES Y METODOLÓGICOS}

El gráfico 4 presenta de forma esquemática el marco de análisis. Así pues, los conceptos clave de renta manejados son cuatro: (i) renta de mercado, (ii) renta bruta, resultado de añadir a la anterior las transferencias sociales monetarias, (iii) renta disponible, al detraer a la anterior los impuestos directos, y (iv) renta disponible extendida, resultado de imputar a la anterior el valor de los servicios públicos en especie.

Como indicador de nivel de vida del hogar se utiliza el concepto de renta del que se trate, dividido por las unidades de consumo del hogar, lo que produce la renta equivalente. Las unidades de consumo se determinan a partir de la escala modificada de la OCDE, que es la utilizada por Eurostat. Finalmente, puesto que nuestra unidad de análisis es el individuo, dicha renta equivalente será atribuida a cada miembro del hogar, lo que en la práctica supone ponderar la renta equivalente por el tamaño del hogar.

Gráfico 4. Esquema analítico para el análisis de la renta del hogar

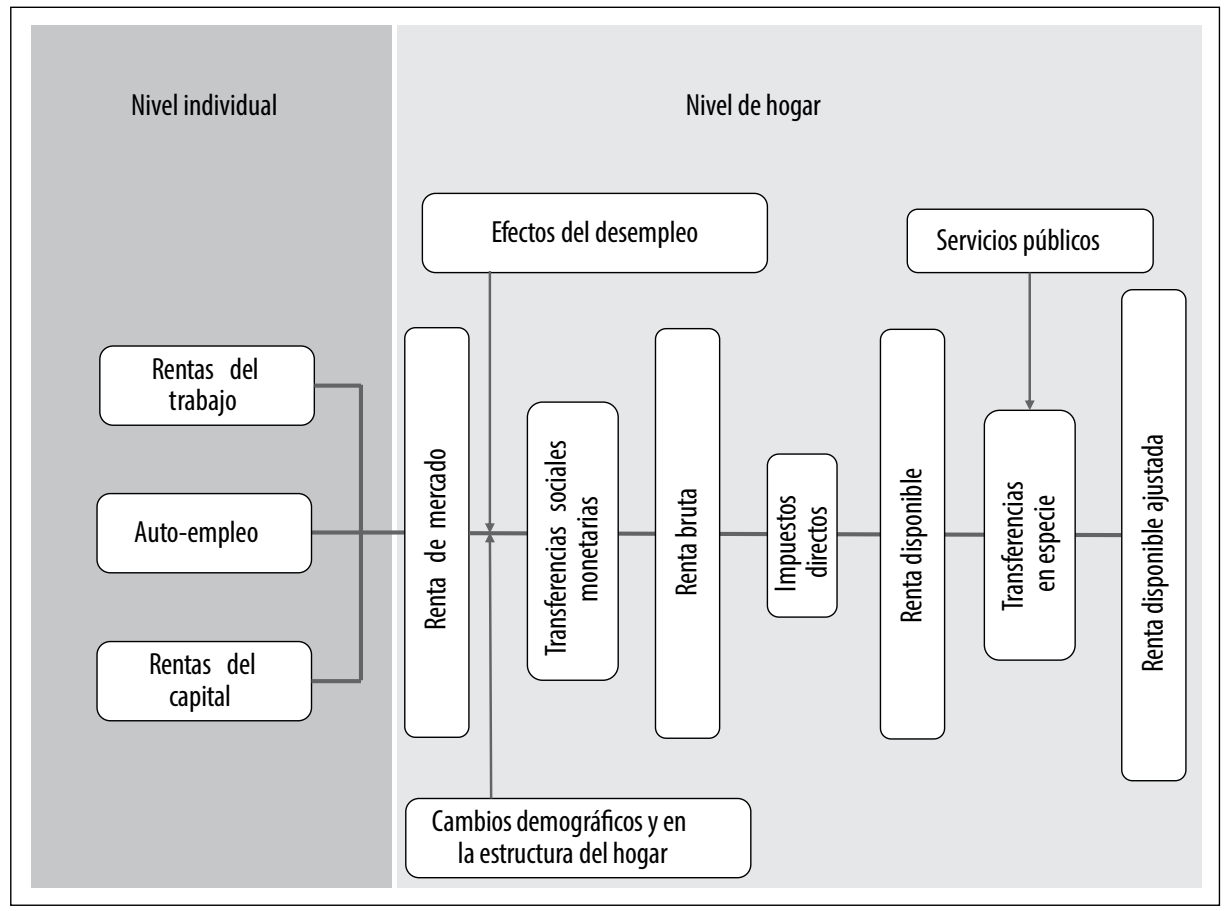

Fuente: elaboración propia

La fuente de información prácticamente exclusiva del trabajo es la ECV, que recoge datos de ingresos, individuales y del hogar, para diversos componentes, 
lo que nos permite obtener los diferentes conceptos de renta que aparecen en el gráfico 4. El período de análisis viene limitado por la disponibilidad de la ECV, y abarca de 2004 a 2013, lo que se corresponde con la ECV de 2005 a 2014, ya que los ingresos vienen desfasados un año.

Los datos sobre servicios de salud y educación, que aparecen en el apartado 5 , proceden de diversas publicaciones de la Intervención General de la Administración del Estado (IGAE), de la Estadística de Gasto en servicios de salud Público (Ministerio de Sanidad, Servicios Sociales e Igualdad) y de las Estadísticas de Gasto Público en Educación (Ministerio de Educación, Cultura y Deporte). Su imputación en los registros de la ECV, efectuada para las comunidades autónomas (CC. AA.), que son las que tienen las competencias en estas materias, se abordará en el apartado 5. Las magnitudes monetarias son deflactadas con el índice de precios al consumo regional (CC. AA.) base 100 en $2011^{2}$.

\section{RENTA DE MERCADO}

Se inicia el recorrido con la evolución de la distribución de la renta de mercado. Aunque el objetivo fundamental del trabajo es el hogar, conviene aclarar que en el origen del proceso la generación de rentas es individual (gráfico 4) y tiene lugar a través de la participación de los individuos en los mercados.

El gráfico 5 muestra la evolución del índice de Gini para los rendimientos brutos mensuales del trabajo a partir del colectivo más homogéneo posible: los asalariados a tiempo completo, para añadir a continuación los asalariados a tiempo parcial y los autónomos ${ }^{3}$, cuya distribución se ha polarizado hasta el extremo durante la crisis. La desigualdad muestra tendencias diversas según el colectivo de trabajadores que constituyan la población de referencia. Para los asalariados a tiempo completo la tendencia hacia una mayor homogeneidad es evidente. En sus inicios, la crisis expulsó del mercado de trabajo a aquellos con menores salarios, de forma que los que permanecían en este colectivo tenían, en promedio, un salario mayor y eran más homogéneos. Añadir a este colectivo los asalariados a tiempo parcial tienden a estabilizar la distribución, e incorporar a los autónomos genera una tendencia hacia una mayor desigualdad. Esta se acentúa si se incluye a los desempleados, sobre todo aquellos que no reciben prestaciones, y el resto de inactivos de la población en edad de trabajar, puesto que estos carecen de ingresos procedentes del mercado.

\footnotetext{
2 La base de datos usada en este trabajo será suministrada a cualquier investigador que la solicite a través de la siguiente dirección electrónica: francisco.j.goerlich@uv.es.

3 Este término hace referencia a los trabajadores independientes y autoempleadores.
} 
Gráfico 5. Índices de Gini: rendimientos del trabajo brutos mensuales según colectivo de trabajadores

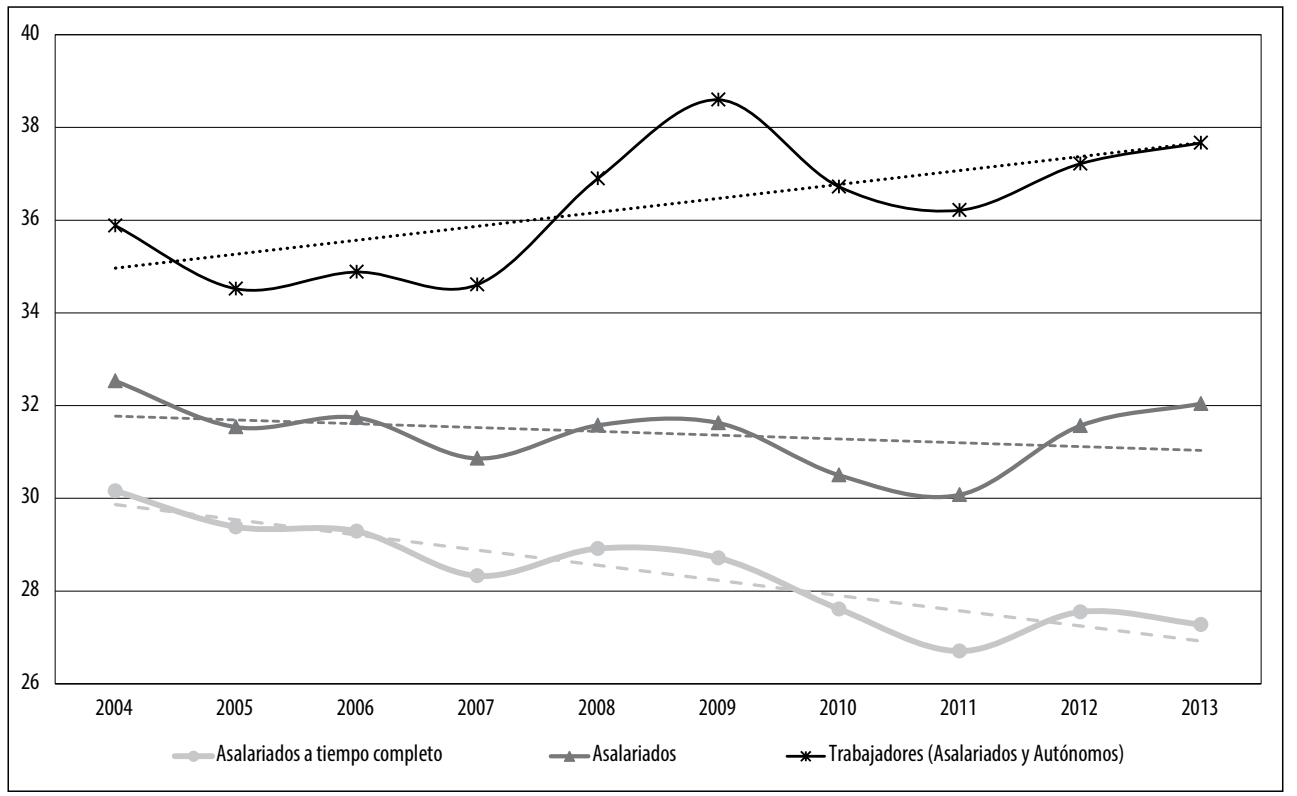

Fuente: elaboración propia a partir de la ECV

El mensaje fundamental del gráfico 5 es que formas precarias de trabajo -empleo a tiempo parcial, por horas o jornadas reducidas- tienden a potenciar la desigualdad, aunque en menor medida que si esas personas permanecieran desempleadas.

El objeto central de este trabajo no es la dispersión salarial, sino la renta del hogar en el contexto del esquema esbozado en el gráfico 4. El gráfico 6 muestra la evolución del índice de Gini para la renta de mercado del hogar. Dos son los hechos que merecen destacarse: (i) la evolución tendencial no es muy diferente de la observada en el gráfico 1 para la renta disponible, y (ii) los niveles de desigualdad son muy elevados. Esto no debe extrañar, y se debe a que muchos hogares no obtienen rentas en el mercado, ya que no participan en él. Por esta razón, el gráfico 6 ofrece también el índice de Gini para la población de hogares con algún miembro en edad de trabajar. El nivel de desigualdad se reduce de forma importante, pero la tendencia se mantiene inalterada, y el deterioro en la distribución es evidente a partir de 2007, con especial intensidad en los años 2008 y 2009. 
Gráfico 6. Índice de Gini: Renta de mercado

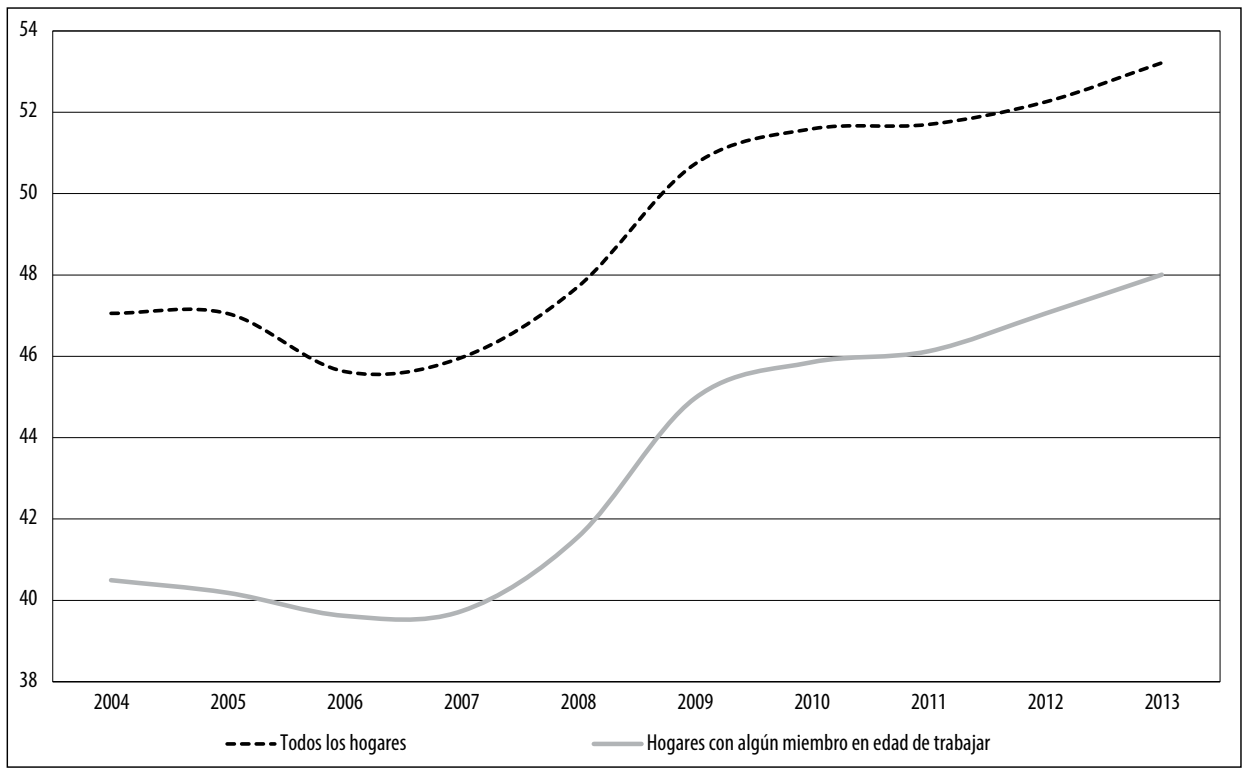

Fuente: elaboración propia a partir de la ECV

La evolución en el nivel y dispersión de la renta de mercado del hogar depende, de forma simplificada, de dos grandes factores: la demografía de los hogares -la formación de nuevas familias, el tamaño del hogar y el emparejamiento selectivo, entre otros- y la evolución del mercado de trabajo -dispersión salarial, horas trabajadas y tasas de empleo, entre otros-.

Si bien el deterioro del mercado de trabajo durante la crisis -la tasa de desempleo pasó del 8,2 \% en 2007 al 26,1 \% en 2013- ha supuesto un claro factor incentivador de las desigualdades ${ }^{4}$, el papel de la demografía de los hogares no es tan evidente. Para tratar de aislar el efecto de ambos factores -demográficos y relativos al mercado de trabajo-sobre la evolución de los índices de desigualdad mostrados en el gráfico 6 cabe preguntarse cuál habría sido la desigualdad si: (i) el tamaño, o (ii) la intensidad de trabajo de los hogares se hubieran mantenido en los niveles de 2004. Utilizar la misma técnica para aislar ambos factores nos permite cuantificar la importancia diferencial de ambos en la tendencia creciente observada en la desigualdad desde 2007.

El procedimiento consiste en re-ponderar las rentas de los hogares al tiempo que se mantiene la estructura de tamaños o la intensidad de trabajo de los mismos $4 \quad$ La correlación entre el índice de Gini de la renta de mercado para los hogares con algún miembro en
edad de trabajar y la tasa de desempleo en el período 2006-2013 es de 0,99. 
observada en 2004, y ver cómo evoluciona el índice de Gini en los años siguientes 5 . Para el tamaño de los hogares se mantiene la estructura de tamaños constante en el nivel de 2004 en todos los años posteriores. Para la intensidad de trabajo, se definen, por persona adulta en edad de trabajar, dos variables que indican el total de meses trabajados y el total de meses potenciales. Estas variables se agregan por hogar, para los adultos a los que les es de aplicación. Por último, se calcula una variable de intensidad de trabajo del hogar como la relación entre los meses trabajados sobre el total potencial. Esta variable se dividió en deciles, más los dos extremos, intensidad nula e intensidad completa, y su estructura se mantuvo constante en los valores de 2004 para los años siguientes, al objeto de aislar los efectos del mercado de trabajo sobre la evolución de la desigualdad.

Los resultados de este experimento contra-factual se muestran en el gráfico 7 y no pueden ser más reveladores. Los aspectos demográficos apenas tienen influencia sobre la evolución de la desigualdad, ya que ambos índices, el observado y el contra-factual, son casi coincidentes, y en ningún año la discrepancia es superior a los 0.3 puntos porcentuales de Gini.

\section{Gráfico 7. Índice de Gini y contrafactuales: renta de mercado}

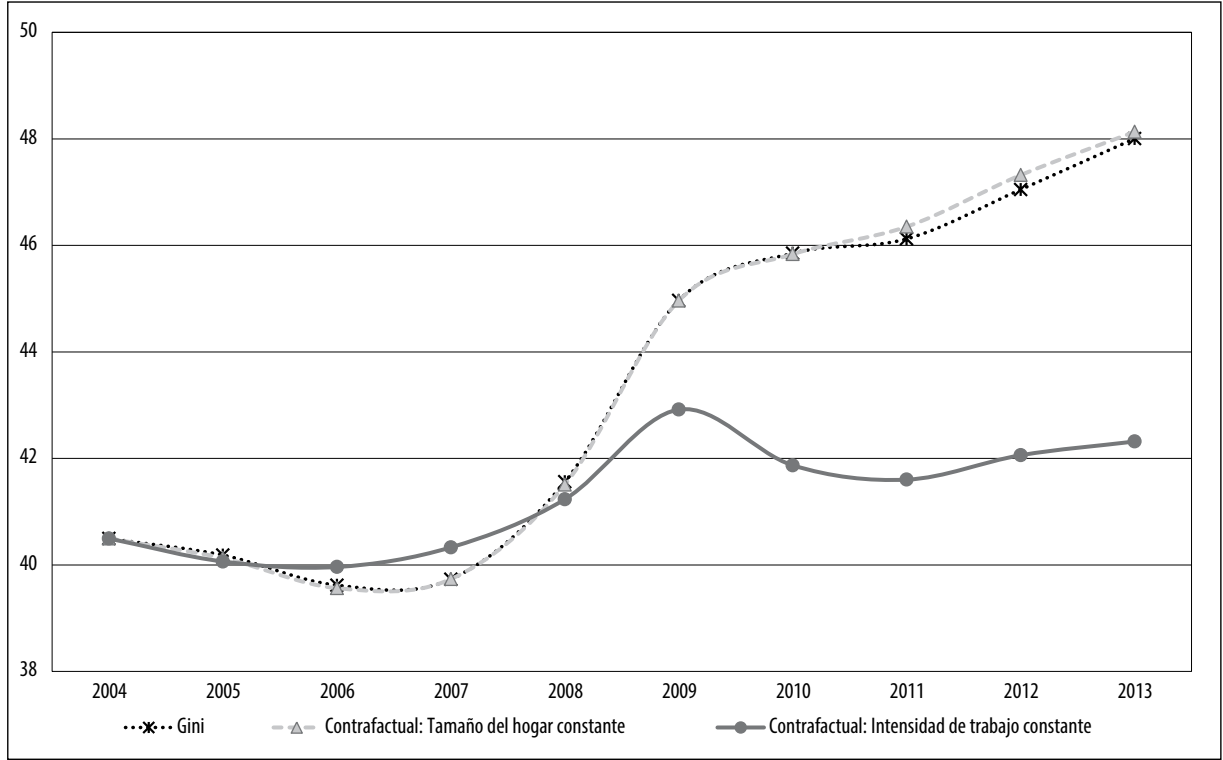

Fuente: elaboración propia a partir de la ECV

\footnotetext{
Los procedimientos de reponderación han recibido una gran atención tras la contribución seminal de Blinder (1973) y Oaxaca (1973), sobre todo en contextos semi-paramétricos, como por ejemplo en los trabajos de DiNardo, Fortin y Lemieux (1996), Biewen (2001) y Cunha, Heckman y Navarro (2006).
} 
Por el contrario, el mantenimiento de la intensidad de trabajo en los niveles anteriores a la crisis hubiera significado crecimientos muy moderados de la desigualdad en términos de la renta de mercado. El índice de Gini hubiera pasado de alrededor de los 40 puntos porcentuales antes de la crisis a solo algo por encima de los 42. De acuerdo con este ejercicio la contribución del desempleo, y en general de la disminución en la intensidad de trabajo, ha contribuido al crecimiento de la desigualdad en la renta de mercado en unos 6 puntos porcentuales de Gini durante el período de crisis, el 75 \% del total. Por el contrario, la evolución en la demografía de los hogares ha sido neutra en términos de sus efectos sobre la distribución.

\section{EL PAPEL REDISTRIBUTIVO DE PRESTACIONES SOCIALES E IMPUESTOS DIRECTOS}

El apartado anterior ha mostrado el aumento en la desigualdad de la renta de mercado a partir de 2007 y ha responsabilizado de este incremento en gran medida a la evolución del mercado de trabajo. La distribución generada por el mercado es solo el primer escalón en el proceso de generación de rentas. Este apartado examina cómo transferencias monetarias e impuestos directos alteran la distribución inicial generada por el mercado. Se analiza primero el efecto redistributivo de las transferencias, para luego examinar el de los impuestos directos. Este es el orden correcto en una sociedad como la española en la que las prestaciones sociales están sujetas a imposición directa.

Las transferencias sociales pueden ser de varios tipos, pero a grandes rasgos es posible distinguir dos grandes grupos: (i) las pensiones de jubilación y vejez, y (ii) el resto de transferencias sociales - prestaciones por desempleo, ayudas de estudios, prestaciones por enfermedad e invalidez, ayudas por familia e hijos, vivienda o asistencia social, entre otros-.

Las prestaciones por jubilación poseen características muy diferentes del resto. Por esta razón, en el paso de la renta de mercado a la renta bruta se efectúa en dos etapas. Primero se añaden las pensiones de jubilación; ello nos permite medir el efecto redistributivo de las mismas sobre la renta de mercado cuando la población de referencia es el conjunto de los hogares - gráfico 6-. A continuación se añade a esta renta el resto de transferencias sociales, lo que permite cuantificar el efecto redistributivo asociado a las mismas.

El gráfico 8 muestra el índice de Gini para diversos conceptos de renta en el paso desde la renta de mercado hasta la renta disponible. Diversos mensajes son de interés.

En primer lugar, se observa que el efecto redistributivo de las prestaciones de jubilación es considerable -del orden de 10 puntos porcentuales de índice de 
Gini-, y estable en el tiempo, y no se aprecian diferencias durante el período de crisis respecto a los años anteriores. Este efecto, ya señalado por otros autores como Cantó (2013) y Roca y Sala (2013), y común a muchos países desarrollados, según el FMI (2014), deriva en última instancia de su importancia cuantitativa, ya que representan alrededor del $75 \%$ del total de transferencias monetarias recibidas por los hogares.

En segundo lugar, el efecto redistributivo del resto de prestaciones sociales es mucho menor, pero lo más importante es que dicho efecto ha aumentado de forma apreciable durante la crisis. Un análisis para los diversos componentes incluidos en este conjunto de transferencias muestra que el aumento en el efecto redistributivo observado en el gráfico 8 asociado a las transferencias sociales, excluidas las prestaciones por jubilación, se debe en su totalidad a las prestaciones por desempleo. Este efecto es muy visible cuando se las considera de forma aislada -línea punteada con triángulos en el gráfico 8-. Ello se debe, en su práctica totalidad, al incremento de su peso en la renta total como consecuencia de la caída en las rentas del trabajo en hogares con desempleados, y ello a pesar de la disminución en la prestación media y la tasa de cobertura. Al final del período las prestaciones por desempleo consiguen reducir, por sí solas, alrededor de 3 puntos porcentuales del índice de Gini.

Gráfico 8. Índice de Gini-De la renta de mercado a la renta disponible: transferencias sociales e impuestos

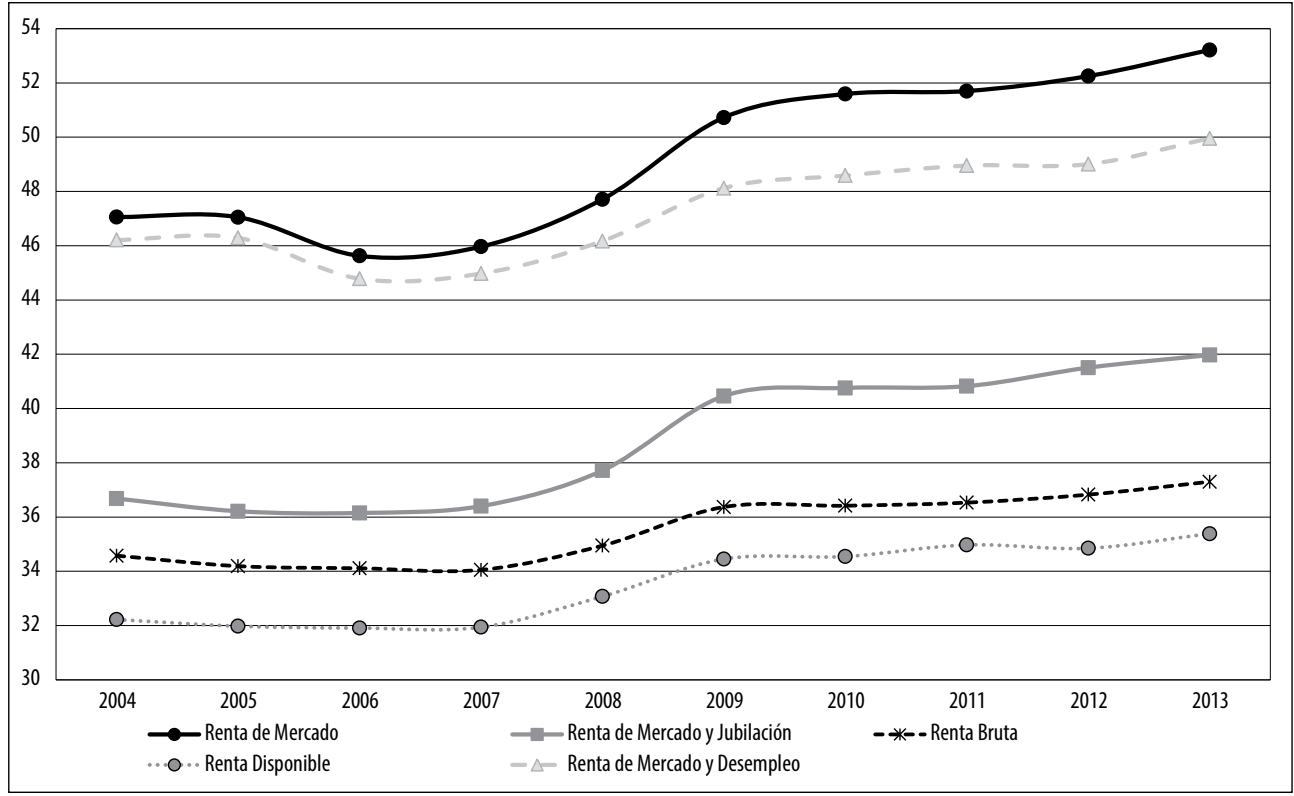

Fuente: elaboración propia a partir de la ECV 
Por último, el gráfico 8 muestra el efecto redistributivo de la imposición directa, tal y como se desprende de la ECV, al contraponer el índice de Gini de la renta bruta con el de la renta disponible, que ya hemos analizado al principio del trabajo. Como no podía ser de otra forma los impuestos directos presentan un comportamiento redistributivo, pero lo más llamativo es que este efecto no solo es menor que el asociado a las prestaciones sociales, incluso cuando excluimos las de jubilación, sino que además este efecto parece haber disminuido ligeramente durante el período de crisis. Si la reducción en el índice de Gini asociada a la imposición directa podía cuantificarse antes de 2007 en una reducción de algo más de 2 puntos porcentuales de Gini, esta reducción es algo inferior después de ese año.

En resumen, la intervención del sector público, vía transferencias sociales e impuestos directos, tiene un impacto sustancial sobre la distribución generada por el mercado en el hogar. El gráfico 8 permite comprobar con nitidez el papel igualador de rentas que ha jugado el sector público, si bien dicho gráfico también pone de manifiesto que este esfuerzo por parte del sector público se ha mostrado insuficiente para frenar las consecuencias del aumento de la desigualdad de la renta de mercado, y cuyo origen se debe al comportamiento del mercado de trabajo.

\section{PROVISIÓN DE SERVICIOS PÚBLICOS EN ESPECIE: SERVICIOS DE SALUD Y EDUCACIÓN}

En las economías desarrolladas modernas los hogares disponen de más recursos de los que pueden ser cuantificados a través de su renta disponible. La razón es que el Estado provee servicios públicos a los ciudadanos que no son pagados por los usuarios directos de dichos servicios públicos, sino que son financiados mediante impuestos. Estos servicios son de muy diversa naturaleza e importancia cuantitativa, pero dos de ellos, los servicios de salud y la educación, destacan por ser fundamentales como mecanismos para garantizar la igualdad de oportunidades. Por otra parte, la cantidad de recursos destinados a estos servicios, que revierten a los ciudadanos, es de una magnitud considerable como para examinar, aunque sea de forma aproximada, qué efectos tienen cuando se imputa el valor de dichos servicios a las rentas de los hogares.

En los últimos años algunos trabajos, entre ellos OCDE (2011) y Vaalauvo (2011), han mostrado el importante efecto de estos servicios públicos, tanto en términos de nivel para la renta de las familias, como en términos redistributivos. También para España existen algunos trabajos en esta dirección desde la década de $1990^{6}$,

\footnotetext{
${ }^{6}$ Pueden consultarse Gimeno (1993, 1999); Ortiz, Abasolo y Jiménez (1999); Calero (2002); Navarro y Hernández (2004); De Pablos y Gil (2011); Patiño (2011) y Calero y Gil (2014).
} 
aunque no suelen tener una perspectiva temporal, ni se dispone de un análisis para el período de crisis reciente. Incorporar los servicios públicos en especie suministrados a los hogares por parte de los poderes públicos no es, sin embargo, frecuente en los análisis distributivos. La razón es simple: investigar esta cuestión no es en modo alguno trivial, y requiere supuestos sobre la valoración de dichos servicios para las familias, determinar criterios de imputación por registro en la ECV, la identificación de los beneficiarios y sus características, y la reconsideración de las economías de escala al comparar hogares heterogéneos. No existe entre la profesión un consenso sobre cómo implementar en la práctica todas estas cuestiones, a las que hay que añadir la disponibilidad de la información pública con el suficiente nivel de desagregación. Por todo ello, los resultados de este ejercicio son meramente indicativos.

Una revisión de la literatura disponible nos permite concluir, no obstante, que a pesar de adoptar diversas aproximaciones metodológicas y distintos criterios de imputación a los hogares, la totalidad de los trabajos obtiene conclusiones similares con independencia de las hipótesis de partida: (i) el gasto en servicios de salud tiene efectos redistributivos y muestra una progresividad importante debido a sus efectos sobre las rentas más bajas, y (ii) la provisión de educación por parte del sector público presenta resultados análogos, aunque en términos cuantitativos la progresividad es menor que la observada para el gasto en servicios de salud, además, dichos efectos se concentran, en su totalidad, en la Educación Primaria y Secundaria, es decir, la educación obligatoria. Nuestras conclusiones no son muy diferentes de estas, incluso para el período de crisis, y se muestran robustas frente a diversas opciones metodológicas.

Se resumen a continuación las opciones metodológicas utilizadas antes de examinar los resultados.

Primero, respecto a la valoración de los servicios públicos se utiliza la forma estándar de valoración, que estima dicho valor monetario en términos del costo de producción de dichos servicios en contabilidad nacional, como lo hacen De Wulf (1981) y Aaberge y Langørgen (2006). Ello significa que el incremento en la renta de los beneficiarios de los servicios públicos se supone igual al costo medio de provisión de los mismos. La principal desventaja de dicho método de valoración es que ignora las diferencias en calidad y eficiencia en la provisión de los servicios públicos.

Segundo, respecto a cómo atribuir los beneficios de los servicios públicos en especie a los hogares, la literatura ha considerado dos enfoques: (i) el denominado enfoque del consumo efectivo, y (ii) el enfoque del valor de seguro, como muestran Marical et al. (2008). Es cierto que no existe un criterio unificado, y la aplicación de un enfoque u otro depende de la naturaleza del bien o servicio suministrado. 
De acuerdo con el enfoque del consumo efectivo el valor medio de la provisión se atribuye al usuario directo del servicio, lo que requiere identificar los beneficiarios de forma precisa en la encuesta donde se efectúe la imputación. Se aplica este enfoque al gasto educativo. De acuerdo con el enfoque del valor de seguro este puede ser más apropiado cuando el servicio público se proporciona con cobertura general, a modo de seguro público; en este caso lo importante no es el uso directo que hacen los ciudadanos del servicio, sino saber que si lo necesitan estará a su disposición. El hecho de que los servicios de salud tengan una cobertura general hace que este enfoque sea mucho más apropiado para el gasto en servicios de salud, que la imputación mediante el uso directo del servicio ${ }^{7}$, por lo que se utilizará este criterio en el caso de los servicios de salud.

En ambos casos la imputación se hace en forma individual, lo que implica que algunos individuos que carecen de rentas monetarias aparezcan con rentas imputadas, por ejemplo, los estudiantes de Primaria. Los valores son imputados por región que es donde se realiza la prestación de estos servicios. Tras la imputación individual, estas rentas se agregan en el hogar, y se aplica la misma escala de equivalencia que hemos venido utilizando hasta ahora, la escala modificada de la OCDE, para determinar la renta equivalente, que finalmente es asignada a cada miembro del hogar.

\subsection{Efectos distributivos de la provisión de servicios en servicios de salud}

La información disponible sobre el gasto en servicios de salud permite distinguir entre 6 funciones, de las cuales solo se considera la imputación para el hogar de las 3 de mayor peso: servicios hospitalarios y especializados, servicios primarios de salud, y farmacia. Estas 3 funciones representan más del $90 \%$ del gasto en servicios de salud, la primera de ellas, más del $50 \%$.

La imputación por registro en la ECV se hace a partir del enfoque del valor del seguro, que distribuye el gasto medio por función entre toda la población de acuerdo con los indicadores de necesidad de servicios de salud por función y grupo de edad que se muestran en el tabla 1. Estos indicadores muestran que la intensidad en la utilización de servicios en servicios de salud es elevada en los primeros años de vida, se reduce durante la juventud y madurez, y se incrementa de forma notable durante la vejez. Así pues, nuestro criterio de imputación solo tiene en consideración las diferencias territoriales y la edad de los individuos, y se ignora cualquier otra

Si este fuera el caso, aquellos con enfermedades más costosas de sufragar se les imputaría una mayor renta, lo que puede carecer de sentido en un momento dado, por ejemplo, en el caso de operaciones puntuales importantes. 
característica observable de los mismos ${ }^{8}$.

Tabla 1. Indicadores de necesidad de servicios de salud por función y grupo de edad

\begin{tabular}{|l|c|c|c|c|c|c|c|}
\cline { 2 - 8 } \multicolumn{1}{c|}{} & \multicolumn{7}{c|}{ Grupo de edad } \\
\cline { 2 - 8 } \multicolumn{1}{c|}{} & $0-4$ & $5-14$ & $15-44$ & $45-54$ & $55-64$ & $65-74$ & +75 \\
\hline Servicios hospitalarios y especializados & 1,19 & 0,26 & 0,52 & 0,84 & 1,34 & 2,20 & 3,12 \\
\hline Servicios primarios de salud & 1,45 & 0,75 & 0,74 & 1,12 & 1,21 & 1,57 & 1,48 \\
\hline Farmacia & 0,21 & 0,15 & 0,25 & 0,69 & 1,39 & 3,21 & 4,30 \\
\hline Total de gasto & 1,03 & 0,43 & 0,55 & 0,90 & 1,29 & 2,18 & 2,76 \\
\hline
\end{tabular}

Fuente: Grupo de trabajo de la conferencia de presidentes para el análisis del gasto en servicios de salud.

Una vez imputado el valor de los servicios en servicios de salud por hogar, para cada una de las funciones consideradas, el gráfico 9 muestra la evolución del índice de Gini en el paso de la renta disponible a la renta extendida con servicios de salud.

\section{Gráfico 9. Índices de Gini-Efectos redistributivos del gasto público en servicios de salud}

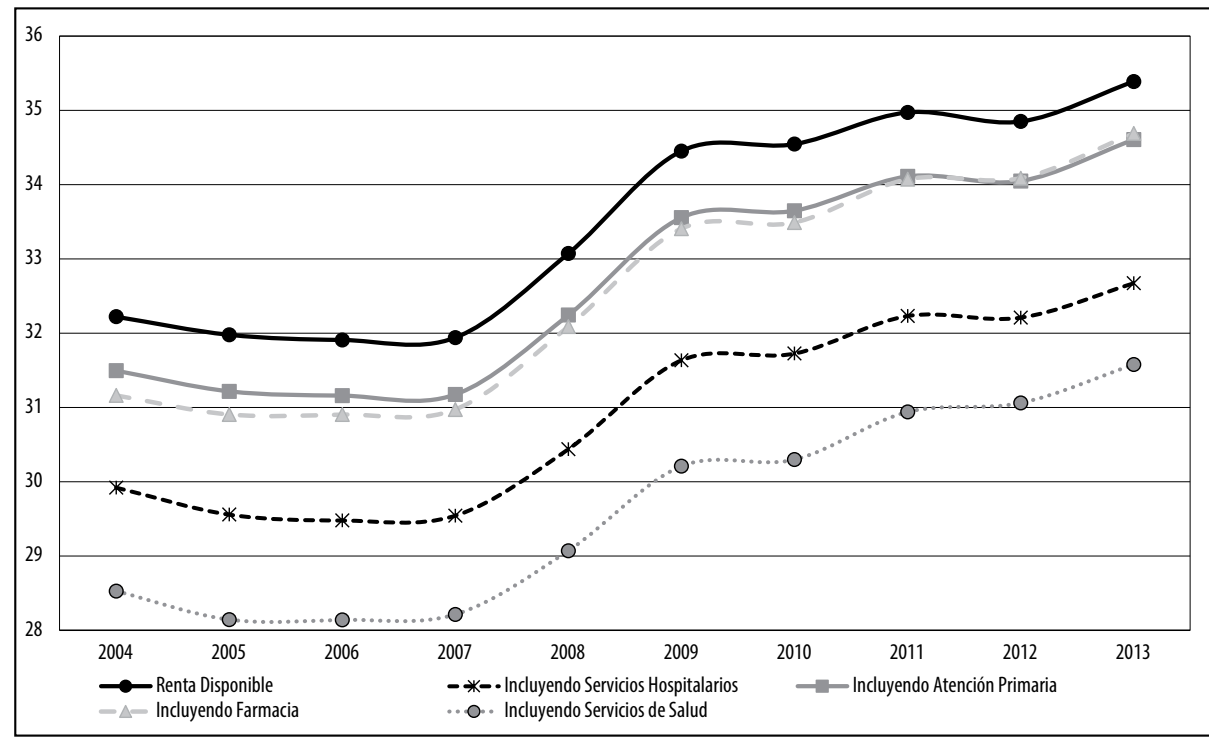

Fuente: elaboración propia a partir de la ECV y estadísticas de la IGAE

8 Incorporar información independiente, procedente de las encuestas de salud, permitiría ser más precisos en la construcción de indicadores de intensidad de servicios de salud, según Calero y Gil (2014); sin embargo, esto va en cierta forma en contra del enfoque del valor del seguro utilizado en la imputación, que toma en cuenta pocas características de los individuos en la determinación de las primas. Por otra parte, los resultados son suficientemente robustos a estas alteraciones metodológicas, ya que nuestros resultados no difieren sustancialmente de lo obtenido por estos autores. 
La imputación del gasto en servicios de salud eleva la renta disponible media en más de un $12 \%$ en todos los años considerados, y reduce el índice de Gini en más de 3 puntos porcentuales. Dicho efecto creció algo en los primeros años de la crisis, 2008 y 2011, cuando la renta de los hogares empezaba a caer, pero el gasto público todavía no lo hacía. Con la disminución del gasto en servicios de salud derivada de las políticas de consolidación fiscal, el efecto redistributivo comienza a caer, para situarse en niveles anteriores a la crisis.

Los hechos más destacables de este ejercicio de imputación del gasto en servicios de salud son los siguientes: primero, la importancia redistributiva del gasto en servicios de salud es considerable, en la medida que reduce de forma sustancial el índice de Gini; por otra parte, no es posible afirmar que dicha importancia se haya visto reducida en el período de crisis. Segundo, a pesar de ello, la inclusión de estas prestaciones en la renta de los hogares no es tan importante como para revertir la tendencia al incremento en las desigualdades observada a partir de 2007. Tercero, por tipo de prestación, el mayor efecto se asocia a los servicios hospitalarios y especializados. La razón es sencilla, la imputación no es función de la renta de los beneficiarios y en esta situación la magnitud del efecto redistributivo depende, en gran parte, de la magnitud del gasto. Servicios primarios de salud y farmacia muestran efectos redistributivos similares, aunque en el caso del gasto farmacéutico se observa una ligera pérdida de intensidad redistributiva en los últimos 2 años, lo que coincide con una reducción del gasto en esta función, según Calero y Gil (2014).

\subsection{Efectos distributivos de la provisión de servicios educativos}

La información disponible sobre educación permite distinguir entre 11 partidas o niveles educativos, de las cuales solo se consideran en nuestro ejercicio los tres grandes niveles: Infantil y Primaria, Secundaria y formación profesional y Universidad. Estos 3 niveles representan algo más del 80 \% del gasto total en educación, y nos permiten identificar de forma directa a los beneficiarios en la ECV ${ }^{9}$. La educación pública se provee tanto en especie como a través de transferencias monetarias, por lo que esta información se depuró de las transferencias monetarias a los hogares al objeto de aislar el efecto del gasto educativo en especie sobre la distribución de la renta. Las trasferencias monetarias, en términos de ayudas al estudio, ya están

\footnotetext{
9 La desagregación proporcionada por la estadística no es; sin embargo, la más apropiada para nuestros propósitos, ya que no es posible una distinción nítida entre la educación obligatoria, entre los 6 y los 15 años, lo que incluye la Primaria y la Educación Secundaria obligatoria (ESO), y el resto de niveles no obligatorios, como la Educación Infantil, el Bachillerato o la Educación Universitaria.
} 
recogidas en las transferencias sociales dentro de la ECV, y por tanto, ya han sido tenidas en cuenta en el apartado anterior.

La imputación por registro en la ECV se hace a partir del enfoque de consumo efectivo, y por tanto, es necesaria una identificación exacta de los estudiantes por nivel educativo en la ECV. Una vez efectuada esta identificación, a cada alumno se le asigna el gasto medio del nivel educativo correspondiente a su CC. AA. de residencia. A grandes rasgos la identificación de los beneficiarios se efectuó de la siguiente forma: (i) Para el período de educación obligatoria, edades comprendidas entre los 6 y los 15 años, ambos incluidos, la imputación se hace por edad, ya se trate de Educación Primaria o Secundaria. (ii) Para las edades en las que la educación no es obligatoria, y si el individuo tiene 5 años o menos, se considera que es beneficiario si declara haber asistido a centros de Educación Pre-escolar o Infantil. (iii) Para las edades en las que la educación no es obligatoria, pero el individuo tiene 16 o más años, la identificación de estudiante se hace cuando declara haber estado estudiando durante algún mes en el período de referencia de la renta. En estos casos si el individuo tiene 16 o 17 años, se le asigna el importe correspondiente a Educación Primaria, si declara estar cursando este tipo de estudios, y el importe correspondiente a Educación Secundaria en otro caso. Si el individuo tiene al menos 18 años, se le asigna el importe correspondiente a Educación Universitaria si declara estar cursando este tipo de estudios.

La principal debilidad de este enfoque de imputación es que no tiene en cuenta la educación privada, imposible de distinguir a partir de la información contenida en la ECV. Sin embargo, en la medida en que este tipo de educación tienda a estar asociada con las clases de renta más elevada nuestros resultados no están sesgados en favor de un mayor efecto redistributivo de este tipo de gasto, sino más bien al contrario $^{10}$.

Una vez imputado el valor de los servicios educativos por hogar, para cada uno de los niveles educativos considerados, el gráfico 10 muestra la evolución del índice de Gini en el paso de la renta disponible a la renta extendida con servicios educativos. La imputación del valor de la educación eleva la renta disponible media en alrededor de un $10 \%$ y reduce el índice de Gini en unos 3 puntos porcentuales, algo menos al principio del período. No existen efectos perceptibles que indique un efecto diferencial antes o después del inicio de la crisis.

\footnotetext{
${ }^{10}$ Al igual que sucede con la salud la incorporación de este aspecto requeriría utilizar fuentes de información complementarias no directamente disponibles
} 
Gráfico 10. Índices de Gini-Efectos redistributivos del gasto público educativo

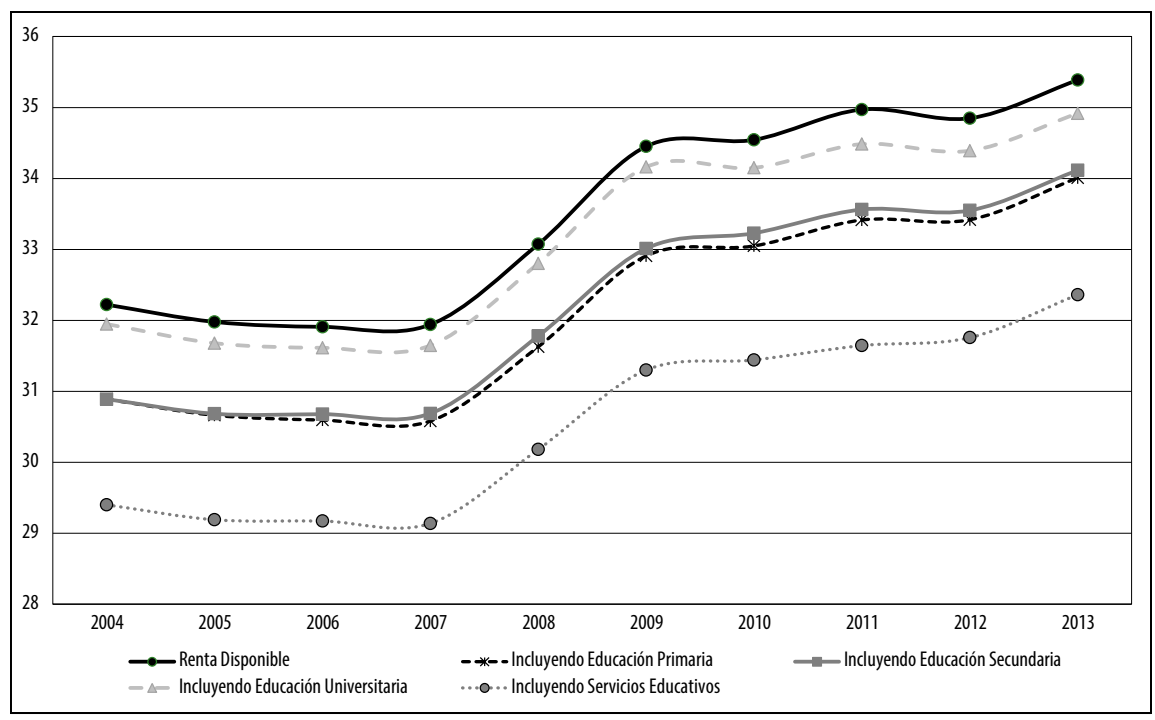

Fuente: elaboración propia a partir de la ECV y estadísticas de la IGAE

Los hechos más destacables de este ejercicio de imputación del gasto educativo son los siguientes: primero, la importancia redistributiva del gasto educativo es considerable, aunque es algo menor, tanto en nivel como en reducción de la desigualdad, que en lo referente al gasto en servicios de salud. Segundo, la inclusión del gasto educativo en la renta de los hogares no revierte la tendencia al incremento de la desigualdad. Tercero, por tipo de educación, los efectos redistributivos se asocian en gran medida a la Educación Primaria y Secundaria, es decir, fundamentalmente a la educación obligatoria, mientras que el efecto redistributivo de la Educación Universitaria es mucho más reducido, resultado que ya ha sido señalado por Patiño (2011), así como por otros autores.

\subsection{Efectos distributivos de la provisión de servicios públicos: servicios de salud y educación}

A modo de síntesis se resume el efecto sobre el nivel medio de renta y su distribución cuando se incorpora tanto el gasto en servicios de salud como en educación en la renta disponible del hogar. Los efectos son contrapuestos, la renta media se incrementa -gráfico 11-, algo por encima del $20 \%$ en términos agregados, y la desigualdad cae -gráfico 12-, por encima de los 6 puntos porcentuales de índice de Gini. En ambos casos los efectos son mayores para los servicios de salud, que para la educación, y no parece que existan efectos diferenciales relevantes antes y después del inicio de la crisis. 
Cabe preguntarse cuál es la razón por la que, en un contexto recesivo, en el que los niveles de renta y, con cierto desfase, también las prestaciones de servicios públicos disminuyen, no se encuentran efectos diferenciales apreciables sobre la distribución antes y durante la crisis. Las razones son dos. Por una parte, la naturaleza de los servicios públicos y el propio sistema de imputación utilizado, que es independiente de la renta de los hogares, e igual en magnitud para cualquier individuo que comparta idénticas características. Por otra parte, nuestro énfasis en el enfoque de la desigualdad relativa, en el que todo lo que importa son las posiciones relativas de los individuos en la escala de rentas. En este caso los deciles inferiores de renta reciben una mayor renta imputada por servicios públicos en términos relativos, debido a sus más bajos niveles de renta disponible, que los deciles superiores, lo que contribuye a la reducción de la desigualdad relativa.

Además, ciertos factores asociados a la estructura demográfica de los hogares tienden a reforzar este efecto amortiguador de las desigualdades. Así, por ejemplo, los hogares situados en los deciles inferiores de renta son más numerosos, y además su valor medio ha crecido en el período analizado. Estos hogares tienen más población escolar, y en consecuencia, se les imputa mayor renta educativa.

Gráfico 11. Renta per cápita equivalente extendida con servicios públicos de servicios de salud y educación

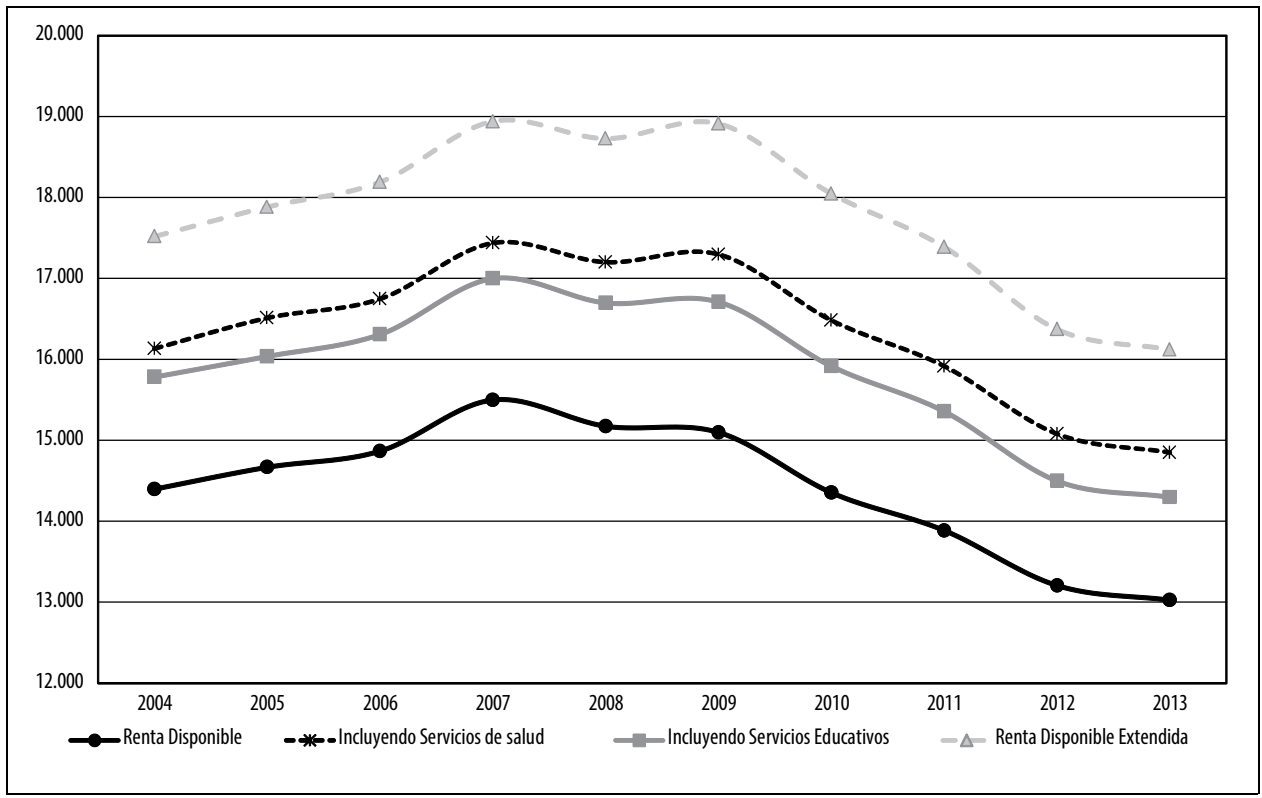

Fuente: elaboración propia a partir de la ECV y estadísticas de la IGAE 
Gráfico 12. Índice de Gini-Efectos redistributivos del gasto público social (servicios de salud y educación)

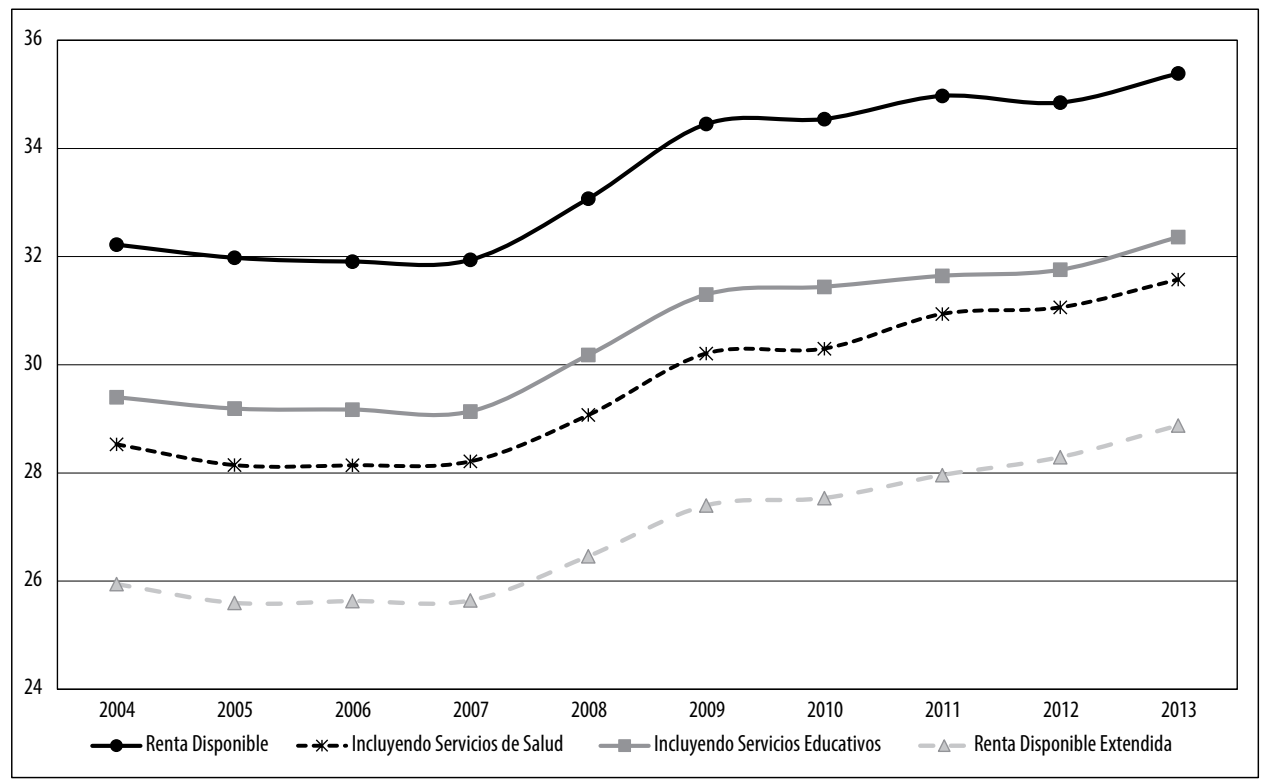

Fuente: elaboración propia a partir de la ECV y estadísticas de la IGAE

\section{CONCLUSIONES}

Este trabajo ha ofrecido una panorámica de la evolución reciente en la distribución de la renta en España en los últimos años. El documento ofrece un recorrido desde la generación de rentas en el mercado en forma individual, hasta el examen de los efectos redistributivos del gasto público en especie, y enfatiza el papel que ha jugado el comportamiento del mercado de trabajo en el incremento observado de las desigualdades, antes y durante la Gran Recesión. Asimismo, se hace hincapié en el papel que las diversas actuaciones públicas tienen en suavizar la distribución inicial que resulta del mercado. La ventaja principal de este enfoque reside en separar los efectos de cada tipo de política: transferencias monetarias, imposición directa y prestación de servicios públicos en especie. La inclusión de estos últimos en el análisis distributivo representa la principal fortaleza del trabajo al mostrar, aunque sea de forma aproximada, el importante papel que estos servicios públicos juegan en la mejora de la distribución y la igualdad de oportunidades.

A modo de resumen, el gráfico 13 ofrece los índices de Gini para las cuatro definiciones de renta utilizadas en el trabajo: renta de mercado, renta bruta, renta disponible y renta disponible extendida con el valor de los servicios pú- 
blicos de salud y educación. Las conclusiones son claras. La evolución reciente del mercado de trabajo está detrás de la evolución en la distribución de la renta de los hogares.

Otras conclusiones relevantes que se desprenden del análisis son las siguientes. Primero, las transferencias monetarias son, en conjunto, las que tienen una mayor capacidad redistributiva. En este contexto destacan, sobre todo, las pensiones, pero también otras prestaciones dirigidas a los estratos más bajos de renta, como han sido, de forma reciente, las prestaciones por desempleo. Segundo, los impuestos directos no muestran un gran efecto redistributivo, sobre todo si se les compara con otro tipo de intervenciones públicas. Tercero, los servicios públicos en especie constituyen una herramienta eficaz para mejorar la distribución, más allá de que su finalidad primordial no sea esta, sino garantizar unos niveles de vida aceptables para todos los ciudadanos. Este efecto redistributivo es asociado en mayor medida a los servicios de salud que a la educación. La principal limitación en la medición de estos efectos redistributivos es que no tienen en cuenta la calidad de los servicios prestados. Cuarto, a pesar de que el gasto público social comenzó a caer en 2010, tres años después del comienzo de la crisis económica, no se observan efectos diferenciales notables sobre la distribución en los últimos años respecto a los años anteriores a la crisis.

\section{Gráfico 13. Índice de Gini para los diversos conceptos de renta}

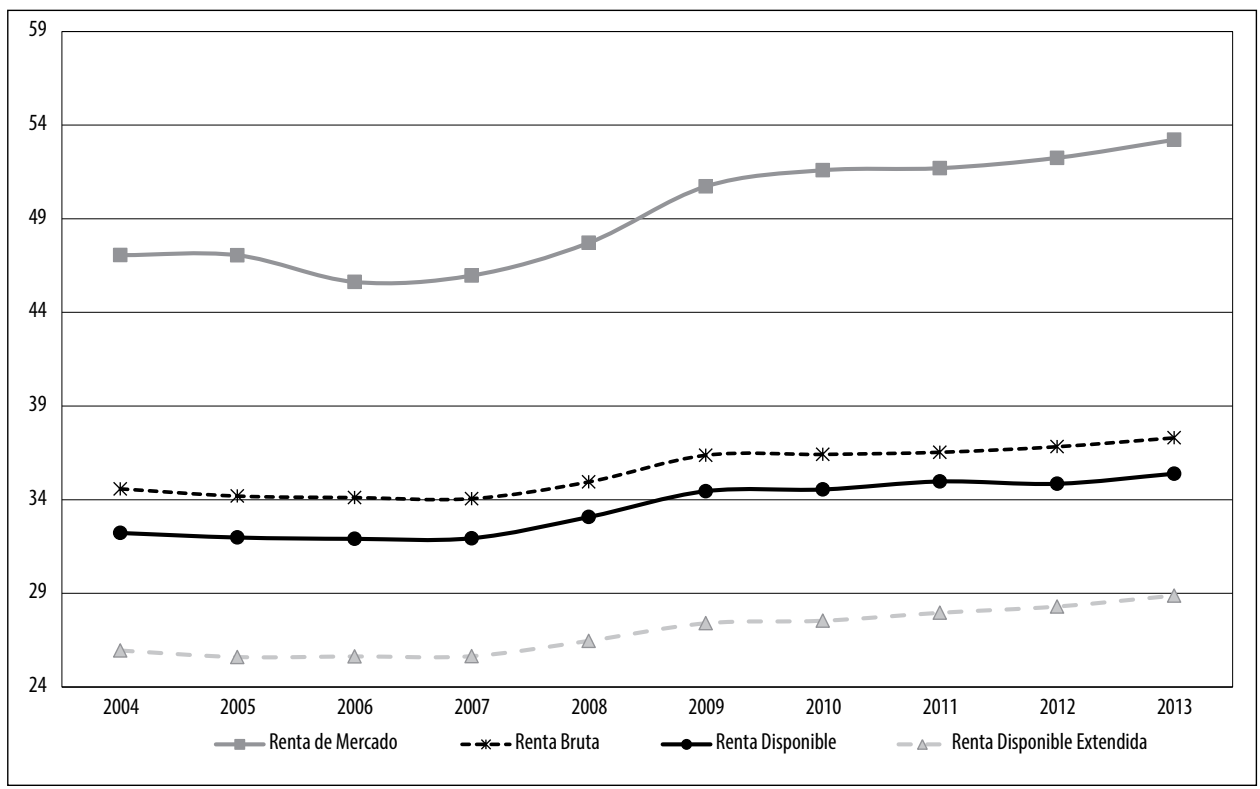

Fuente: elaboración propia a partir de la ECV y estadísticas de la IGAE 
No obstante, aunque los efectos de las políticas de consolidación fiscal sobre la desigualdad relativa podrían describirse como moderados, en el sentido de que mantienen el efecto redistributivo antes y después de 2007, no sería acertado argumentar que los programas de ajuste fiscal no han tenido efectos sobre el bienestar de los ciudadanos. La razón es que en este contexto, no solo la distribución relativa de recursos importa, sino también los niveles de renta, y la escala en la reducción de los niveles ha sido importante en muchos casos, en especial para los hogares en la parte baja de la distribución, tal y como muestra el gráfico 3.

\section{BIBLIOGRAFÍA}

Aaberge, R. y Langørgen, A. (2006). Measuring the benefits from public services: The effects of local government spending on the distribution of income in Norway. En: The Review of Income and Wealth, Vol. 52, No. 1, marzo, p. 61-83.

Ayala Cañón, L. (2013). Crisis económica y distribución de la renta: una perspectiva comparada. En: Papeles de Economía Española, No. 135, abril, p. 2-19.

Ayala Cañón, L. (2014). Desigualdad y pobreza en España en el largo plazo: la continuidad de un modelo. Documento de Trabajo No. 2.1, Madrid: Fundación Fomento de Estudios Sociales y de Sociología Aplicada (Foessa), VII Informe sobre exclusión y desarrollo social en España, 47p.

Ayala Cañón, L. (2016). La desigualdad en España: fuentes, tendencias y comparaciones internacionales. Estudios sobre la Economía Española. No. 2016/24, Madrid, FEDEA y Revista $\overline{\text { Libros, 61p. }}$

Blinder, A. S. (1973). Wage discrimination: Reduce form and structural estimates. En: Journal of Human Resources, Vol. 8, No. 4, p. 550-559.

Biewen, M. (2001). Measuring the Effects of Socio-Economic Variables on the Income Distribution: An Application to the East German Transition Process. En: Review of Economics and Statistics, Vol. 83, No. 1, febrero, p. 185-190.

Bucheli, M.; Lustig, N.; Rossi, M. y Amábile, F. (2014). Social spending, taxes, and income redistribution in Uruguay. En: Public Finance Review, Vol. 42, No. 3, p. 413-433.

Calero Martínez, J. (2002). The distributive incidence of public social expenditure in Spain. En: Social Policy and Administration, Vol. 36, No. 5, p. 443-464.

Calero Martínez, J. y Gil Izquierdo, M. I. (2014). Un análisis de la incidencia distributiva del gasto público en sanidad y educación en España. Documento de Trabajo No. 2.8, Madrid: Fundación Foessa (Fomento de Estudios Sociales y de Sociología Aplicada), VII Informe sobre exclusión y desarrollo social en España, 27p.

Cantó, O. (2013). La capacidad redistributiva del sistema español de prestaciones e impuestos Papeles de Economía Española, No. 135, abril, p. 140-152. 
Cunha, F.; Heckman, J. J. y Navarro, S. (2006). Counterfactual Analysis of Inequality and Social Mobility, p. 290-348. En: S. L. Morgan; D. B. Grusky y G. S. Fields (Eds.). Mobility and Inequality: Frontiers of Research in Sociology and Economics. Stanford, CA (EE. UU.): Stanford University Press, 488p.

De Pablos Escobar, L. y Gil Izquierdo, M. (2011). Impacto distributivo del gasto público en educación universitaria en España: un análisis de incidencia normativa para el nuevo milenio. En: Estudios de Economía Aplicada, Vol. 29, No. 1, p. 1-33.

De Wulf, L. (1981). Incidence of Budgetary outlays: Where do we go from here? En: Public Finance, Vol. 36, No. 1, p. 55-76 [versión disponible en español: De Wulf, L. (1987). Incidencia del gasto: ¿Hacia dónde vamos ahora? En: Hacienda Pública Española, No. 107, p. 107-120].

DiNardo, J.; Fortin, N. M. y Lemieux, T. (1996). Labor Market Institutions and the Distribution of Wages, 1973-1992: A Semiparametric Approach. En: Econometrica, Vol. 64, No. 5, septiembre, p. 1001-1044.

Gimeno, J. A. (1993). Incidencia del gasto público por niveles de renta (España 1990 vs. 1980). En: Sector público y redistribución: I Simposio sobre igualdad y distribución de la renta y la riqueza. Vol. VII, Madrid: Fundación Argentaria, p. 63-123.

Gimeno, J. A. (1999). La incidencia redistributiva de las prestaciones públicas en especie: Sanidad y educación (España-1990). En: J.M. Maravall Herrero (Coord.). Políticas de Bienestar y Desempleo: III Simposio sobre Igualdad y Distribución de la Renta y la Riqueza. Vol. II, Madrid: Fundación Argentaria y Ed. Visor, p. 15-68.

Goerlich, F. J. (2016). Distribución de la renta, crisis económica y políticas redistributivas. Bilbao: Fundación BBVA, 244p.

Higgins, S. y Pereira, C. (2014). The Effects of Brazil's Taxation and Social Spending on the Distribution of Household Income. En: Public Finance Review, Vol. 42, No. 3, p. 346-367.

FMI -Fondo Monetario Internacional- (2014). Fiscal policy and income inequality. IMF Policy Paper, Washington (DC), enero, 68p.

Jaramillo, M. (2014). The incidence of social spending and taxes in Peru. En: Public Finance Review, Vol. 42, No. 3, p. 391-412.

Lusting, N. y Pessino, C. (2014). Social Spending and Income Redistribution in Argentina during the 2000s. En: Public Finance Review, Vol. 42, No. 3, p. 304-325.

Marical, F.; Mira D'ercole, M.; Vaalavuo, M. y Verbist, G. (2008). Publicly provided Services and the Distribution of Households' Economics Resources. En: OECD Journal: Economic Studies, Vol. 44, No. 2008/1, diciembre, París: OECD Publishing, p. 1-38.

Navarro Espigares, J. L. y Hernández Torres, E. (2004). La incidencia del gasto público sanitario en España: Un meta-análisis. En: Estudios de Economía Aplicada, Vol. 22, No. 2, p. 317-348.

Oaxaca, R. (1973). Male-Female Wage Differentials in Urban Labour Markets. En: International Economic Review, Vol. 14, No. 3, p. 693-709.

OCDE - Organización para la Cooperación y el Desarrollo Económicos - (2011). Divided We Stand: Why Inequality Keeps Rising. París: OECD Publishing, 400p. 
OCDE (2014). Rising inequality: youth and poor fall further behind. Insights from the OECD Income Distribution Database. Income Inequality Update, junio. París: OECD Directorate for Employment, Labour and Social Affairs, Statistics Directorate, 8p.

OCDE (2015). In It Together Why Less Inequality Benefits All. París: OECD Publishing, 396p.

Ortiz, F.; Abasolo, I. y Jiménez, V. I. (1999). Sanidad pública y distribución de la renta en España, p. 69-102. En: J.M. Maraval (Ccoord.). Políticas de Bienestar y Desempleo. III Simposio sobre Igualdad y Distribución de la Renta y la Riqueza. Vol. II, Madrid: Fundación Argentaria y Ed. Visor, 524p.

Patiño Rodríguez, D. (2011). La incidencia del gasto público en educación sobre la distribución del bienestar económico. En: Hacienda Pública Española/Revista de Economía Pública, Vol. 199, No. 4, p. 119-148.

Prados de la Escosura, L. (2008). Inequality, poverty and the Kuznets curve in Spain, 1850 - 2000. En: European Review of Economic History, Vol. 12, p. 287-324.

Roca Sagalés, O. y Sala, H. (2013). Efectos distributivos del sistema fiscal desde una perspectiva macroeconómica. En: Papeles de Economía Española, No. 135, abril, p. 184-199.

Stiglitz, J. E.; Sen, A. y Fitoussi, J. P. (2009). Report by the Commission on the Measurement of Economic Performance and Social Progress. CMEPSP, French Government, 292p.

Vaalauvo, M. (2011). Towards an Improved Measure of Income Inequality. The Impact of Public Services in Income Distribution. Tesis doctoral, Florencia (Italia): Instituto Universitario Europeo, Department of Political and Social Sciences, 247p. 